\title{
Libros recomendados
}

Rosario Cumplido Corbacho

Editora Revista SEEO. Hospital Virgen del Rocío, Sevilla.

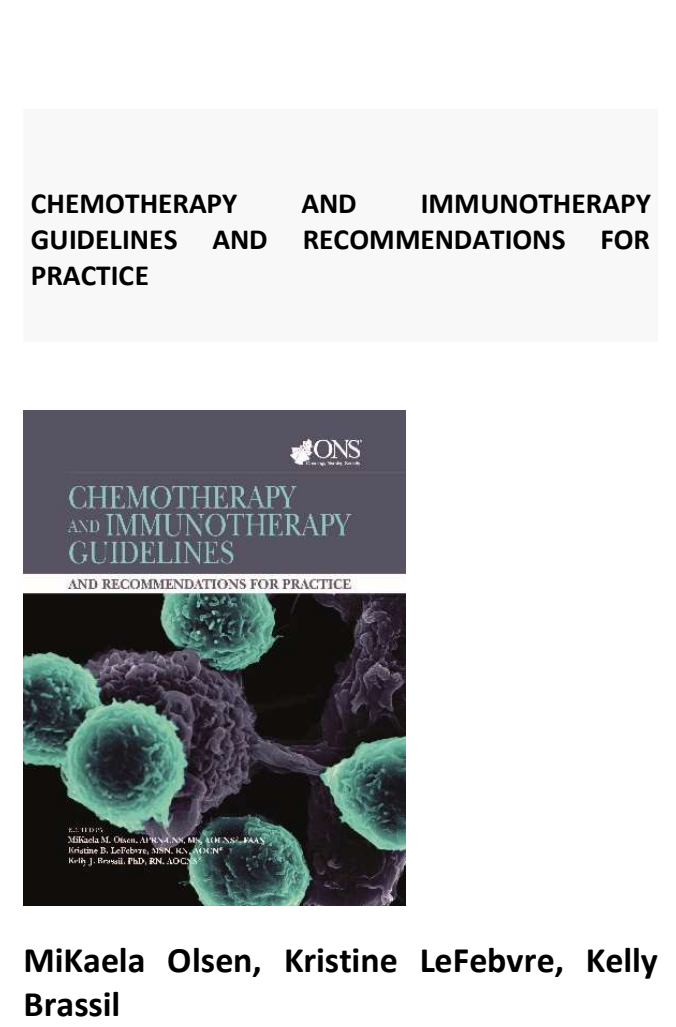

Editorial: ONCOLOGY NURSING SOCIETY

Año de publicación: 2019

ISBN: 978-1-635-93020-7

La Sociedad de Enfermería Oncológica es un referente en cuanto a guías y educación basadas en la evidencia para la administración de quimioterapia y el manejo de los efectos secundarios. Este texto completamente revisado y incluye los últimos avances relacionados con la atención de enfermería de pacientes que reciben terapias antineoplásicas.

Las pautas y recomendaciones de práctica de quimioterapia e inmunoterapia se distribuyen en 26 capítulos que desarrollan las diferentes terapias contra el cáncer: quimioterapia, inmunoterapia, agentes dirigidos molecularmente y terapia hormonal.

En estos capítulos encontrará información y características acerca de:

- Fisiopatología y manejo de toxicidades relacionadas con el tratamiento antineoplásico, con guías basadas en evidencia.

- Información sobre los efectos secundarios de la inmunoterapia y su manejo.

- Administración segura de terapias contra el cáncer, incluido un capítulo sobre prevención y manejo de reacciones relacionadas con la infusión, igualmente aportando estrategias actuales basadas en evidencia.

- Tablas completas de medicamentos en cada capítulo y figuras, tablas y algoritmos nuevos y actualizados.

- Consideraciones profesionales como el alcance y los estándares de práctica, educación profesional, políticas y procedimientos, seguridad de la medicación antineoplásica, cuestiones éticas y legales y educación del paciente.

Estas pautas explican y hacen referencia a estándares que las enfermeras de oncología deben conocer y seguir. Este libro es una guía esencial para mejorar su atención a los pacientes con cáncer. 


\section{¿QUÉ ES EL CÁNCER?}

\section{La única manera de combatir un mal es conocerlo.}

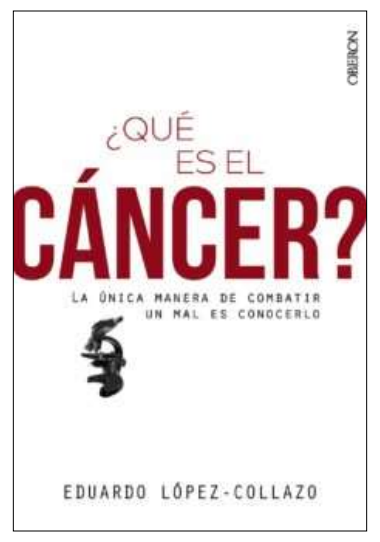

\section{Eduardo López-Collazo}

Editorial: OBERON

Año de publicación: 2019

ISBN: 978-84-415-4087-3

Se trata de una obra adecuada para recomendar a nuestros pacientes, una obra apta para todos los públicos, sin importar el nivel de información previo acerca del tema, ya que debido al amplio conocimiento del autor acerca del cáncer, consigue simplificarlo y hacerlo extremadamente accesible $y$ entendible para todos.

Eduardo López-Collazo es físico nuclear y doctor en Inmunología, actualmente es el director científico del Instituto de investigación sanitaria del Hospital La Paz (IdIPaz), pero además dirige su propio grupo de investigación en Tumor-inmunología, o lo que es lo mismo, las interacción existente entre nuestro sistema inmune y los tumores. Sin embargo, tiene una notable vocación divulgativa que le ha llevado a escribir de una forma magistralmente accesible acerca del cáncer, en el convencimiento de que "conocer un mal es la única manera de combatirlo".

El libro entrelaza historias reales con datos científicos, consiguiendo la atención e, incluso podríamos decir, la implicación del lector. Muestra, además, la forma de trabajar de un grupo de investigación.

Algún día dejaremos de hablar del cáncer o -aún mejor- no le tendremos miedo. Pasará como con la sífilis, la polio y otras tantas dolencias que huelen a pasado y se eliminan de un plumazo, es decir, con una vacuna o un antibiótico. Sin embargo, para que ese día llegue, todos tenemos que hacer algo. La única manera de combatir un mal es conocerlo. Ese es el propósito de este libro. Estas páginas ayudarán a entender qué es el cáncer, por qué ocurre, qué hacemos para curarlo, cómo podemos prevenirlo, cuál es su futuro. Sin palabras incomprensibles ni términos futuristas. 


\section{LA COMUNICACIÓN CENTRADA EN LA PACIENTE DE CÁNCER DE MAMA: ENTENDER Y SER ENTENDIDO}

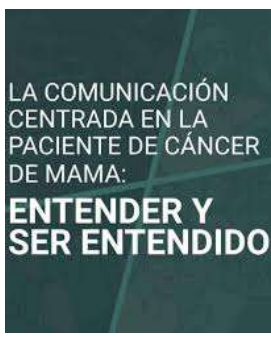

\section{Diego Alejandro Utor Fernández}

Editorial: Publicaciones SESPM (Sociedad Española de Senología y Patología Mamaria)

Año de publicación: 2018

ISBN: 978-84-09-05451-0

Los tratamientos del cáncer de mama afectan a las mujeres que padecen esta enfermedad en todos los ámbitos de su vida, desde la autoestima, hasta su esquema corporal, las relaciones personales y sociales, e incluso en el aspecto laboral. Por eso -según el cirujano de la Unidad de Patología Mamaria del Hospital Puerta del Mar, Diego Alejandro Utor Fernández-, es muy importante que haya una buena comunicación entre el profesional sanitario y estas pacientes.

Para mejorar la comunicación entre el profesional sanitario y las pacientes con cáncer de mama durante todo el proceso de la enfermedad, este cirujano ha elaborado un breve manual titulado "La comunicación centrada en la paciente de cáncer de mama: entender y ser entendido". Se trata de "una ayuda para que un profesional sepa qué debe hacer y qué debe evitar en la comunicación con el paciente", explica su autor.
El manual recoge cuestiones enfocadas a cómo dar el diagnóstico a las pacientes, cómo informar de un mal pronóstico, cómo responder a las reacciones emocionales, cómo fomentar las decisiones compartidas - cómo responder a las situaciones conflictivas, con el objetivo que las pacientes participen en su propio proceso expresando sus decisiones y deseos, acepten mejor los tratamientos y los resultados y tengan unas expectativas más reales.

En esta obra han colaborado la cirujana coordinadora de la Unidad de Patología Mamaria del Puerta del Mar, Pilar Moreno Paredes, el cirujano de esta Unidad Isabelo Serrano Borrero, la psiquiatra de la Unidad de Salud Mental del hospital gaditano María del Carmen Granados Sánchez y la psicooncóloga coordinadora del voluntariado de la Asociación Española Contra el Cáncer en el Puerta del Mar Ana Cruz Fuentes. Las ilustraciones las ha realizado de forma desinteresada Rubén Sánchez Moreno.

El manual, del cual se hicieron mil copias para distribuirlas gratuitamente en hospitales españoles, está accesible en el enlace:

https://www.sespm.es/wpcontent/uploads/2018/11/GuiaSESPM2.pdf 